\title{
Hydrogen Breath Testing Predicts Bowel Preparation Quality Prior to Colonoscopy: A Systematic Review
}

\author{
Arjun R. Sondhi ${ }^{\mathrm{a}, \mathrm{d}}$, e, Jacob E. Kurlander ${ }^{\mathrm{a}, \mathrm{b}}$, d, Stacy B. Menees ${ }^{\mathrm{a}, \mathrm{b}}$, \\ Sameer D. Sainia, c
}

\begin{abstract}
Background: This systematic review aims to assess the accuracy of hydrogen breath testing as a predictor of bowel preparation.

Methods: Studies were identified from MEDLINE, Embase, Web of Science, Cochrane Library and clinicaltrials.gov. Two investigators evaluated abstracts for inclusion criteria - report of correlation between hydrogen breath levels and bowel preparation quality, prospective design and non-emergent colonoscopy in adults. Included studies underwent duplicate data extraction using a standardized approach. The Quality Assessment of Diagnostic Accuracy Studies (QUADAS-2) tool assessed quality of the studies.
\end{abstract}

Results: One hundred fifty-nine publications were identified, and six unique studies met inclusion criteria. The number of patients analyzed ranged from 61 to 127 . Three studies were performed in the USA, one in Japan and two in Italy. Three studies used a prebiotic in addition to a purgative, with the intention of enhancing the discriminating ability of hydrogen breath levels. Three studies assessed baseline hydrogen levels. In five of the six studies, hydrogen breath levels were predictive of inadequate bowel preparation. Suggested absolute hydrogen levels to distinguish adequate from inadequate bowel preparation ranged from 3 to 10 parts per million. Depending on the cutoff value, sensitivity ranged from $71 \%$ to $100 \%$ and specificity from $87 \%$ to $100 \%$. There was significant heterogeneity among studies in breath testing protocol and breath analyzer used. Full-text studies had low risk of bias in most assessed domains.

Conclusion: Hydrogen breath levels predict bowel preparation adequacy but existing studies have significant limitations. Further studies

Manuscript submitted August 24, 2018, accepted September 7, 2018

aDepartment of Internal Medicine, Division of Gastroenterology, University of Michigan, Ann Arbor, MI, USA

bVeterans Affairs Ann Arbor Health Care System, Ann Arbor, MI, USA

'Veterans Affairs Center for Clinical Management Research, Ann Arbor, MI, USA

${ }^{\mathrm{d} C}$ Co-primary authors

${ }^{\mathrm{e} C o r r e s p o n d i n g ~ A u t h o r: ~ A r j u n ~ R . ~ S o n d h i, ~ U n i v e r s i t y ~ o f ~ M i c h i g a n, ~} 1500$ East Medical Center Drive, Ann Arbor, MI 48109, USA.

Email: sondhia@med.umich.edu

doi: https://doi.org/10.14740/gr1078w should use standardized methods and consider the real-world practicality of self-administered home breath testing.

Keywords: Colonoscopy; Bowel preparation; Quality; Hydrogen; Breath test

\section{Introduction}

Inadequate bowel preparation is a prevalent and persistent problem in the endoscopy unit. Even with state-of-the-art split-dose bowel preparations, $15-20 \%$ of patients have inadequate preparation at the time of colonoscopy [1]. Inadequate preparation results in multiple clinical and economic harms, including decreased adenoma and cancer detection, repeat procedures, patient burden and increased cost [2-4]. Thus, a fail-safe strategy based solely on the prevention of inadequate preparation remains elusive. An appealing parallel strategy is detection of patients with inadequate bowel preparation before they incur the risk and expense of sedation and colon intubation. Such an approach could be used to rapidly triage patients with inadequate preparation to interventions, such as same-day consumption of additional preparation.

One novel technique to detect bowel preparation quality is hydrogen breath testing (HBT). This test holds theoretical appeal - fermentable substrates passing from the small bowel into a bacteria-rich colon produce hydrogen gas, which is then absorbed into the blood stream and exhaled. Exhaled hydrogen would be expected to decrease after a successful bowel preparation, potentially offering a quantifiable measure of the adequacy of bowel preparation without instrumentation. Indeed, several small studies have suggested that HBT accurately predicts preparation quality prior to colonoscopy [5-9]. Given the appropriate technology, HBT could even be used either to help patients tailor the amount of purgative they consume at home, or to identify patients with inadequate preparation once they reach the endoscopy unit.

We sought to systematically review the literature for studies examining the diagnostic test characteristics of HBT for inadequate bowel preparation. Through this work, we hoped to assess the quality of the existing literature on this topic and derive summary estimates of the diagnostic test characteristics of HBT for inadequate bowel preparation. 


\section{Materials and Methods}

\section{Study selection}

We developed a systematic search strategy with the assistance of a medical librarian (MC). We submitted our protocol to PROSPERO, an international prospective database of systematic reviews, which approved it before we commenced our search (PROSPERO 2015: CRD42015017806). We searched MEDLINE, Embase, Web of Science, the Cochrane Library, and clinicaltrials.gov from database inception to May 2016. Embase was also used to identify abstracts from meetings of the American Gastroenterology Association, the American Society of Gastrointestinal Endoscopy and the American College of Gastroenterology. Clinicaltrials.gov was searched to identify recently completed or ongoing trials. Studies were not restricted by language. The search strategy included the terms "colonoscopy", "breath test" and "hydrogen breath test", or synonyms of those terms. The full search strategy is provided in the Supplementary 1.

Studies were included if they met the following criteria: 1) testing of hydrogen breath levels with the intention of predicting bowel preparation quality; and 2) performance of colonoscopy to formally assess bowel preparation quality (the gold standard). Studies were not restricted by the bowel preparation scale, the breath testing substrate or protocol that was used.

Two physicians from our team (AS and JK) independently screened all abstracts to determine whether they met inclusion criteria. When an abstract appeared to meet inclusion criteria, the full-text article, if one existed, was reviewed. Any disagreement on inclusion was adjudicated by a third-team member (SS). For studies that appeared relevant but published only in abstract form, we contacted the authors for additional information.

\section{Data extraction}

A structured form was created to extract variables of interest, including study location and design, patient selection strategy, colonoscopy indication, age, gender, dietary changes, bowel purgative, timing of breath testing, substrate (e.g. lactulose, inulin, fiber), breath test analysis equipment, preparation quality scale, suggested hydrogen-level cutoffs and diagnostic test characteristics.

\section{Quality assessment}

Methodological quality was assessed using the Quality Assessment of Diagnostic Accuracy Studies (QUADAS-2) tool [10], which is recommended by the Cochrane handbook for the assessment of the accuracy of diagnostic tests [11]. This tool focuses on four domains: patient selection, index test, reference standard, and patient flow and index test timing. Two investigators (AS and JK) independently performed the quality assessment and agreed upon low, medium or high risk of bias for each study. Low risk for bias was defined as no more than two combined "unclear" or non-low (any bias greater than low risk) results in the domain assessment. Medium risk for bias was defined as three to four combined "unclear" or non-low results in the domain assessment. High risk for bias was defined as 5 or more combined "unclear" or non-low results in the domain assessment.

\section{Role of funding sources}

This work was performed without external funding.

\section{Results}

\section{Literature search}

One hundred fifty-nine potentially relevant publications, including abstracts and full-text articles, were identified (Fig. 1). Six unique studies met inclusion criteria, including four from full-text articles and two published only in abstract form. No additional studies were identified after reviewing the references of full-text articles or after searching for articles that subsequently cited any of the six studies.

\section{Study characteristics}

The characteristics of the six studies are shown in Table 1. Altomare et al reported on two distinct studies in a single publication; therefore, two entries are included for this publication [5]. Three studies were performed in the USA, two in Italy and one in Japan. The number of patients analyzed ranged from 61 to 127 . Three of the six studies did not report the colonoscopy indication $[6,8,9]$. The remaining studies included colonoscopies that were performed for a variety of indications, including diagnosis, screening and surveillance. A variety of pre-procedure diets were used including carbohydrate-free diet, clear liquids followed by overnight fasting or usual diet followed by overnight fast. Two studies did not comment on dietary changes $[8,9]$. Three studies used a prebiotic (inulin, lactulose, FiberCon) in addition to a purgative, with the intention of enhancing the discriminating ability of hydrogen breath levels $[5,7,9]$. Only three studies assessed baseline hydrogen levels [5, 7, 9]. Five of the studies stated which HBT equipment was used, but no studies used the same equipment [5-8].

Significant variation existed in the timing of HBT relative to colonoscopy. For example, Urita et al measured baseline hydrogen levels on the morning of the procedure and then every 15 min until colonoscopy was initiated. In contrast, Altomare et al measured baseline hydrogen levels 1 week prior to colonoscopy and again at $5 \mathrm{~min}$ before the bowel preparation and 5 min before the colonoscopy, which allowed for exclusion of $\mathrm{H}_{2}$ non-producers. Meyer et al did not specify the exact timing of $\mathrm{HBT}$ relative to the procedure.

The studies used a variety of bowel preparation regimens. 


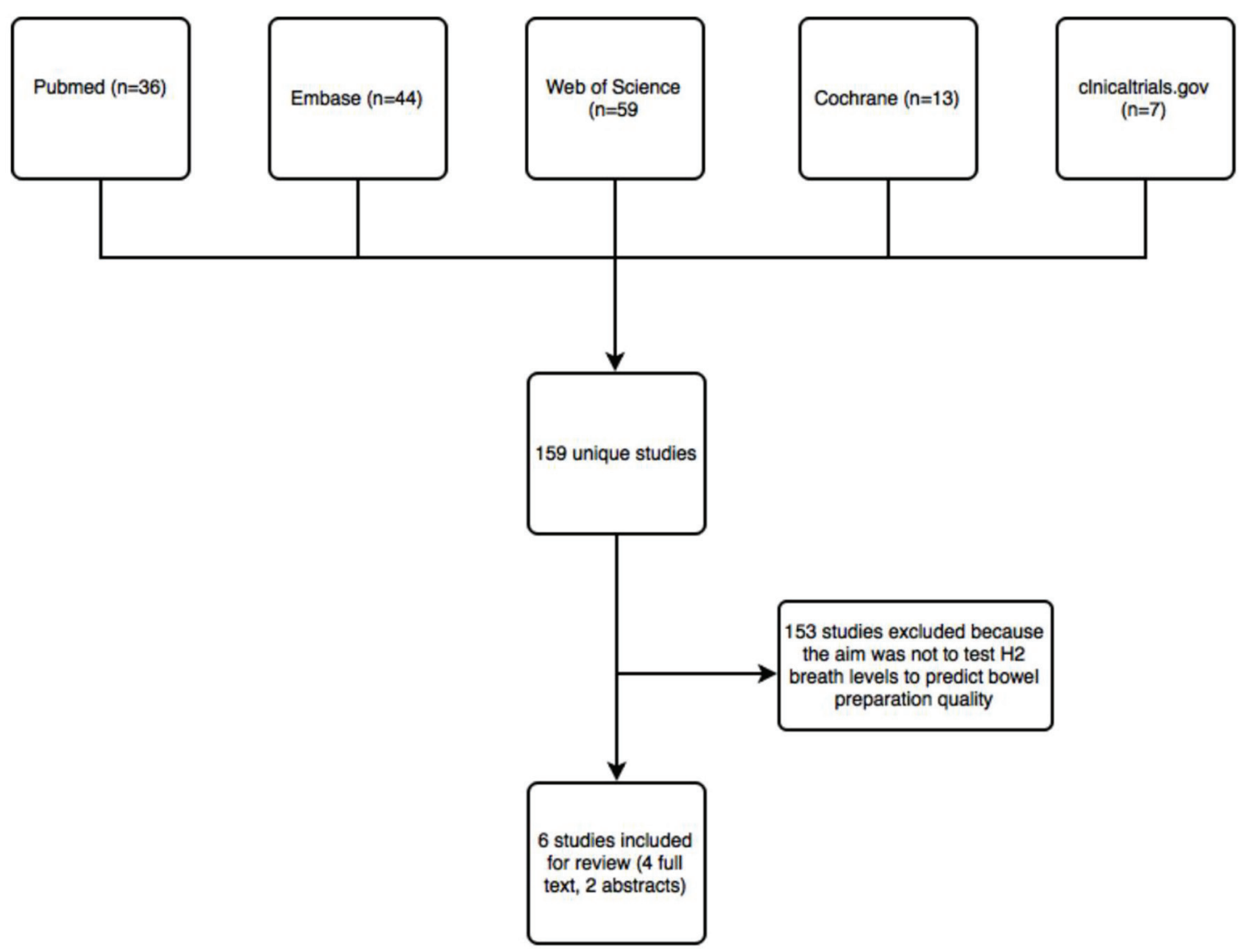

Figure 1. Flow chart of studies identified by literature search.

Four studies used polyethylene glycol (PEG), one study used various preparations, including Fleet's phosphosoda, visicol and golytely, and one study did not state which purgative was used. No study used a standardized, validated bowel preparation scale such as the Ottawa, Aronchick or Boston Bowel Preparation scales [12]. Instead, four studies used excellent/ fair/poor and two studies used a 1 - 5 scale, with 1 being the cleanest and 5 being the least clean.

\section{HBT outcomes}

Table 2 describes the HBT outcomes for each study. In five of the six studies, hydrogen breath levels were significantly different between adequately and inadequately prepared patients. Both studies by Altomare et al showed a significant reduction in hydrogen levels after preparation. Mann et al showed a significantly lower hydrogen breath level in the fair-to-excellent preparation group relative to the poor preparation group. One study by Meyer et al showed that hydrogen levels were lower in the adequately prepared group relative to the inadequate group, while a separate study by the same author did not find any difference.

Table 3 lists the suggested hydrogen cutoff level (to discriminate between adequate versus inadequate preparation), whenever reported, as well as the statistical analyses each study performed. Suggested absolute hydrogen level cutoffs to distinguish adequate from inadequate bowel preparation ranged from 3 to 10 parts per million (ppm). Depending on the cutoff value, sensitivity ranged from $72 \%$ to $100 \%$ and specificity ranged from $87 \%$ to $100 \%$. Positive predictive value (PPV) ranged from $69 \%$ to $100 \%$. Negative predictive value (NPV) ranged from $78 \%$ to $100 \%$. Due to substantial variation in breath testing methods among studies, a meta-analysis was unable to be performed.

\section{Study quality and risk of study bias}

Table 4 shows the results of the QUADAS-2 assessment. The two studies by Altomare et al were considered as one for the purposes of quality assessment since the methods were identical. The Altomare et al's and Urita et al's studies were scored as low risk for overall bias, and the Mann et al's and Meyer et al's studies were scored as medium risk for overall bias. No study had an individual domain or overall assessment as high risk for bias. The most common reasons for an escalation from low risk to medium risk for bias was lack of clarity in the reported methods. Specific examples include failure to describe whether consecutive patients or a random sample was enrolled, the interval between the colonoscopy and HBT, or whether all enrolled patients were included in the analysis. 

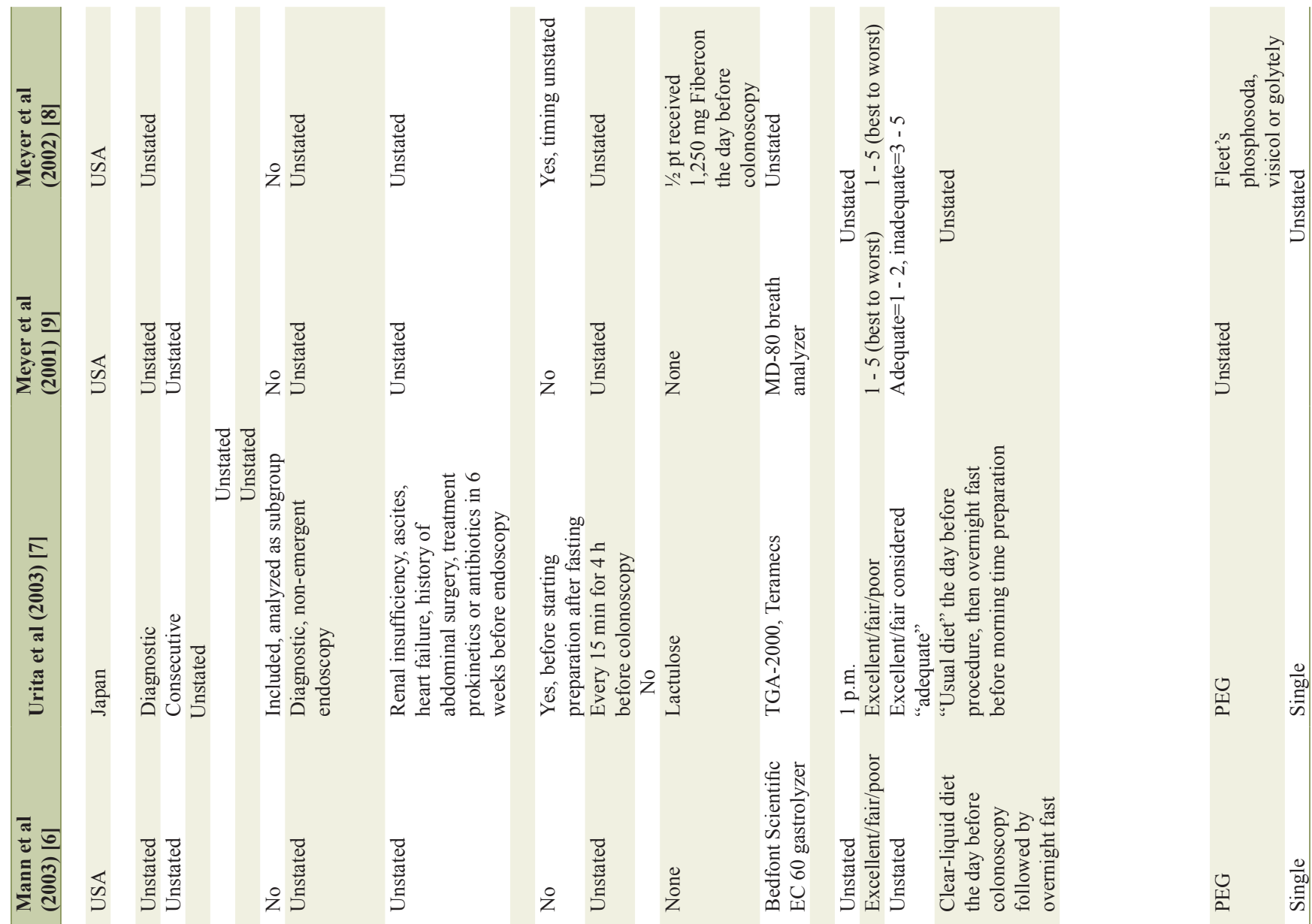

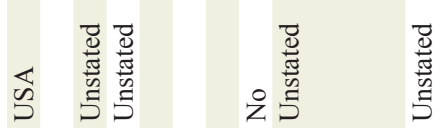

$\because \frac{1}{1}$

过造

离点
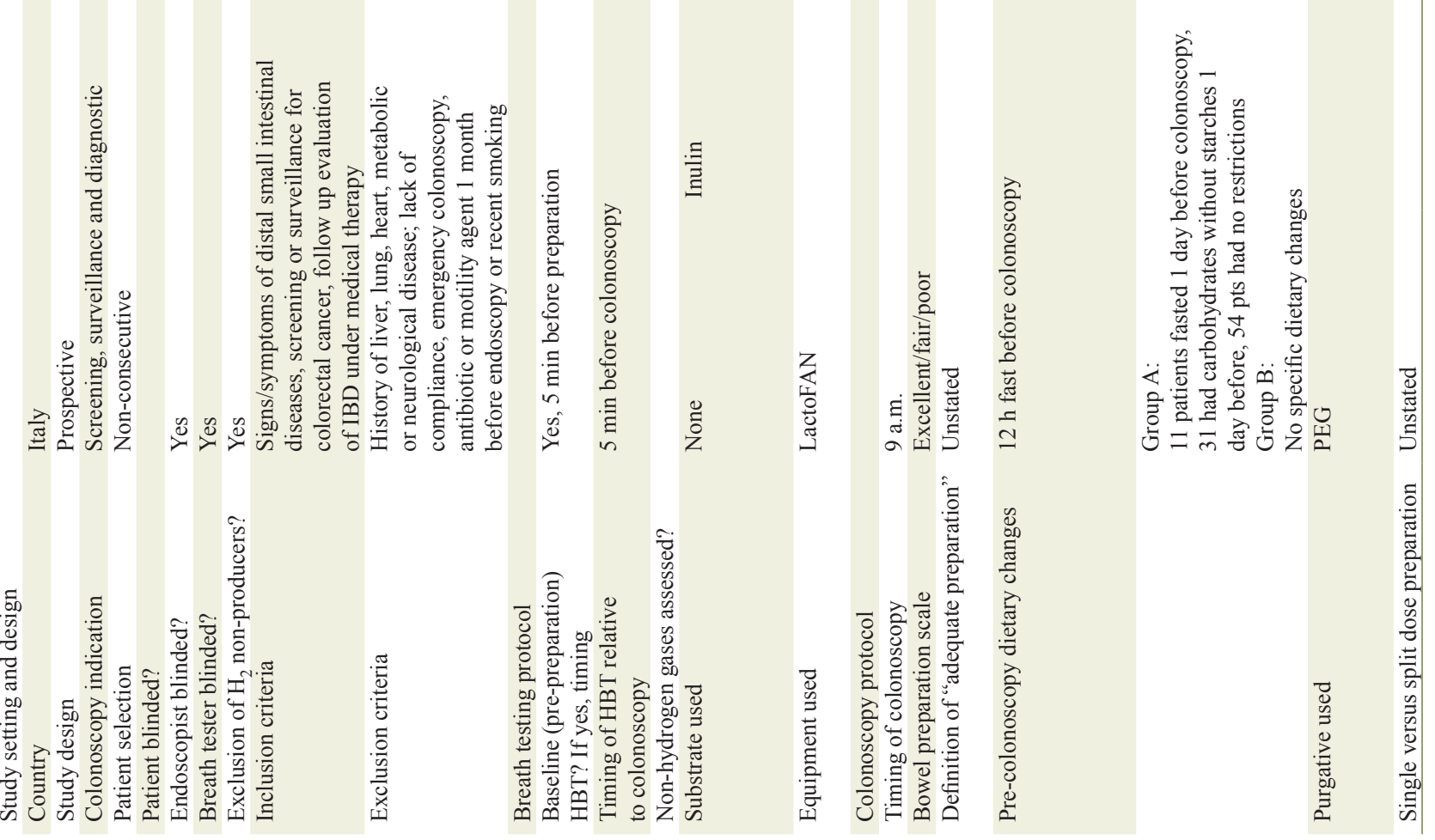


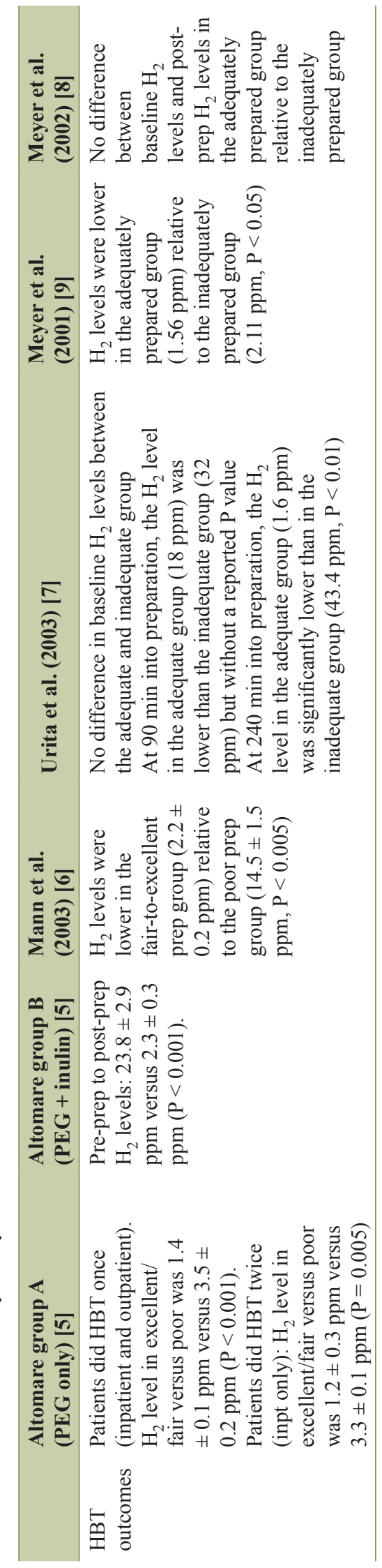

\section{Discussion}

Inadequate bowel preparation has been a persistent problem in endoscopy units despite incremental improvements from better formulations and timed dosing of bowel purgatives [1]. The clinical and economic harms associated with this problem are legion: missed cancers, repeat procedures, excess health system cost, patient inconvenience and risk, and endoscopy unit inefficiency [13-15]. A strategy that could detect patients who have had inadequate bowel preparation before the colonoscopy starts could stem many of the harms associated with inadequate bowel preparation. We reviewed all studies to date that have examined the performance of HBT for this purpose. We found that five of six studies demonstrated significant differences in hydrogen breath levels between adequately and inadequately prepared patients. Furthermore, multiple different breath testing protocols, involving the use of carbohydrate substrates, or none at all, were used successfully. Our systematic review suggests the future promise of hydrogen breath testing for detecting inadequate bowel preparation. With future studies clarifying a dominant strategy, the use of hydrogen breath testing may represent a possible paradigm shift for how endoscopy units identify inadequate bowel preparation prior to sedation and instrumentation.

Previous attempts at identifying patients with inadequate bowel preparation before procedure start have been unsuccessful. While appealing because of low cost, low risk and ease of use, the appearance of fecal effluent and patient self-report have proven unreliable predictors of bowel preparation quality $[16,17]$. Alternatively, the US Multi-Society Task Force recommends that preliminary assessment of preparation quality be made endoscopically in the rectosigmoid colon with termination of procedures in which the bowel preparation is inadequate to detect polyps $>5 \mathrm{~mm}$ [18]. However, endoscopic assessment of bowel preparation still incurs substantial expense and (typically) sedation risk simply to make a determination of preparation adequacy. Several clinical prediction models have been developed to identify patients who are high risk for inadequate bowel preparation $[19,20]$. However, these are more appropriately used to tailor the selection of the bowel preparation regimen, not for post-preparation assessment of adequacy.

While the results of our review suggest that pre-colonoscopy HBT is extremely promising, additional, more robust studies are needed to confirm the accuracy and feasibility of this testing strategy. Specifically, future studies should use rigorous methods, including endoscopist blinding and standardized bowel preparation scales. Future research into precolonoscopy breath testing should also be mindful of implementation strategies. For ease of use in practice, breath testing would ideally be done at a single time point and without the need for a carbohydrate substrate. The studies reviewed suggest that this is possible, which should be confirmed in the future. It will also be important to consider where and how breath testing can be integrated into current pre-colonoscopy practices. If breath testing is done at the time of patient arrival in the endoscopy unit, there will need to be protocols for how to administer additional purgative or reschedule the patients for another time. Breath testing at home prior to departure for 
Table 3. Statistical Analysis and Proposed Hydrogen Level Cutoffs for Poor Bowel Preparation

\begin{tabular}{|c|c|c|c|c|c|c|}
\hline & $\begin{array}{l}\text { Altomare group } \\
\text { A (PEG only) [5] }\end{array}$ & $\begin{array}{l}\text { Altomare group B } \\
(\mathrm{PEG}+\text { inulin })[5]\end{array}$ & $\begin{array}{l}\text { Mann et al } \\
(2003)[6]\end{array}$ & Urita et al (2003) [7] & $\begin{array}{l}\text { Meyer et al } \\
(2001)[9]\end{array}$ & Meyer et al (2002) [8] \\
\hline $\begin{array}{l}\mathrm{H}_{2} \text { cutoff value } \\
\text { suggested (ppm) }\end{array}$ & 3 & 3 & 5 & $\begin{array}{l}10 \text { at } 90 \text { and } 240 \mathrm{~min} \\
\text { into prep ingestion }\end{array}$ & Unstated & $\begin{array}{l}\text { N/a since no difference } \\
\text { was found }\end{array}$ \\
\hline Sensitivity (\%) & 72 & 83 & 96.7 & 100 & & \\
\hline Specificity (\%) & 93 & 87 & 87.5 & 100 & & \\
\hline NPV (\%) & 93 & 93 & 77.8 & 100 & & \\
\hline AUROC/c-statistic & Not available & 0.93 & Not available & Not available & & \\
\hline
\end{tabular}

the endoscopy unit has appeal, but it is unclear how this could be carried out feasibly.

Our review has several strengths and limitations. First, we used a comprehensive search strategy that included both fulltext studies as well as abstracts. Additionally, we examined and reported breath testing protocols in great detail, which likely contributed to observed differences in results among studies and will be useful in guiding future studies of this topic. A notable limitation is that multiple studies were unclear in their patient selection process and endoscopist blinding. Another limitation of the review is that meta-analysis with summary estimates of results could not be conducted given the significant heterogeneity of study designs. Lastly, our results are subject to the same threats to validity that exist in the constituent

Table 4. QUADAS-2 [10] Assessment

\begin{tabular}{|c|c|c|c|c|c|}
\hline & $\begin{array}{l}\text { Altomare et al } \\
\text { (both studies) [5] }\end{array}$ & Mann et al (2003) [6] & Urita et al (2003) [7] & $\begin{array}{l}\text { Meyer et al } \\
(2001) \text { [9] }\end{array}$ & Meyer et al (2002) [8] \\
\hline $\begin{array}{l}\text { Overall } \\
\text { QUADAS-2 } \\
\text { rating }\end{array}$ & Low risk of bias & Medium risk of bias & Low risk of bias & Medium risk of bias & Medium risk of bias \\
\hline $\begin{array}{l}\text { Domain } \\
1 \text { (patient } \\
\text { selection) }\end{array}$ & $\begin{array}{l}\text { Unclear if selection } \\
\text { introduced bias; } \\
\text { overall low concern } \\
\text { that included patients } \\
\text { did not match the } \\
\text { review question }\end{array}$ & $\begin{array}{l}\text { Unclear if selection } \\
\text { introduced bias; } \\
\text { overall low concern } \\
\text { that included patients } \\
\text { did not match the } \\
\text { review question }\end{array}$ & $\begin{array}{l}\text { Low risk of selection } \\
\text { introducing bias; } \\
\text { overall low concern } \\
\text { that included patients } \\
\text { did not match the } \\
\text { review question }\end{array}$ & $\begin{array}{l}\text { Unclear if selection } \\
\text { introduced bias; } \\
\text { overall low concern } \\
\text { that included patients } \\
\text { did not match the } \\
\text { review question }\end{array}$ & $\begin{array}{l}\text { Unclear if selection } \\
\text { introduced bias; } \\
\text { overall low concern } \\
\text { that included patients } \\
\text { did not match the } \\
\text { review question }\end{array}$ \\
\hline $\begin{array}{l}\text { Domain } 2 \\
\text { (index test) }\end{array}$ & $\begin{array}{l}\text { Low risk that } \\
\text { conduction or } \\
\text { interpretation of } \\
\text { the index test could } \\
\text { have introduced bias; } \\
\text { low concern that the } \\
\text { index test, its conduct } \\
\text { or interpretation } \\
\text { differed from the } \\
\text { review question }\end{array}$ & $\begin{array}{l}\text { Low risk that } \\
\text { conduction or } \\
\text { interpretation of } \\
\text { the index test could } \\
\text { have introduced bias; } \\
\text { low concern that the } \\
\text { index test, its conduct } \\
\text { or interpretation } \\
\text { differed from the } \\
\text { review question }\end{array}$ & $\begin{array}{l}\text { Low risk that } \\
\text { conduction or } \\
\text { interpretation of } \\
\text { the index test could } \\
\text { have introduced bias; } \\
\text { low concern that the } \\
\text { index test, its conduct } \\
\text { or interpretation } \\
\text { differed from the } \\
\text { review question }\end{array}$ & $\begin{array}{l}\text { Low risk that } \\
\text { conduction or } \\
\text { interpretation of } \\
\text { the index test could } \\
\text { have introduced bias; } \\
\text { low concern that the } \\
\text { index test, its conduct } \\
\text { or interpretation } \\
\text { differed from the } \\
\text { review question }\end{array}$ & $\begin{array}{l}\text { Low risk that } \\
\text { conduction or } \\
\text { interpretation of } \\
\text { the index test could } \\
\text { have introduced bias; } \\
\text { unclear concern that } \\
\text { the index test, its } \\
\text { conduct or interpretation } \\
\text { differed from the } \\
\text { review question }\end{array}$ \\
\hline $\begin{array}{l}\text { Domain } 3 \\
\text { (reference } \\
\text { standard) }\end{array}$ & $\begin{array}{l}\text { Low risk that the } \\
\text { reference standard, } \\
\text { its conduct or } \\
\text { interpretation could } \\
\text { have introduced } \\
\text { bias; low concern } \\
\text { regarding the target } \\
\text { condition matching } \\
\text { the review question }\end{array}$ & $\begin{array}{l}\text { Unclear risk that the } \\
\text { reference standard, } \\
\text { its conduct or } \\
\text { interpretation could } \\
\text { have introduced } \\
\text { bias; low concern } \\
\text { regarding the target } \\
\text { condition matching } \\
\text { the review question }\end{array}$ & $\begin{array}{l}\text { Unclear risk that the } \\
\text { reference standard, } \\
\text { its conduct or } \\
\text { interpretation could } \\
\text { have introduced } \\
\text { bias; low concern } \\
\text { regarding the target } \\
\text { condition matching } \\
\text { the review question }\end{array}$ & $\begin{array}{l}\text { Unclear risk that the } \\
\text { reference standard, } \\
\text { its conduct or } \\
\text { interpretation could } \\
\text { have introduced } \\
\text { bias; low concern } \\
\text { regarding the target } \\
\text { condition matching } \\
\text { the review question }\end{array}$ & $\begin{array}{l}\text { Unclear risk that the } \\
\text { reference standard, its } \\
\text { conduct or interpretation } \\
\text { could have introduced } \\
\text { bias; low concern } \\
\text { regarding the target } \\
\text { condition matching } \\
\text { the review question }\end{array}$ \\
\hline $\begin{array}{l}\text { Domain } 4 \\
\text { (flow and } \\
\text { timing) }\end{array}$ & $\begin{array}{l}\text { Low risk that patient } \\
\text { flow introduced bias }\end{array}$ & $\begin{array}{l}\text { Unclear risk that patient } \\
\text { flow introduced bias }\end{array}$ & $\begin{array}{l}\text { Low risk that patient } \\
\text { flow introduced bias }\end{array}$ & $\begin{array}{l}\text { Unclear risk } \\
\text { that patient flow } \\
\text { introduced bias }\end{array}$ & $\begin{array}{l}\text { Unclear risk that patient } \\
\text { flow introduced bias }\end{array}$ \\
\hline
\end{tabular}


studies.

In conclusion, our systematic review suggests that precolonoscopy hydrogen breath testing has high discriminant ability to differentiate patients with adequate versus inadequate bowel preparation, and that a range of carbohydrate substrates may be used, or even none at all. Further research in this area could potentially lead to a more proactive, effective and safer means to ensure every patient achieves adequate bowel preparation.

\section{Acknowledgments}

We acknowledge Marisa Conte, the Assistant Director of Research and Informatics Unit for the Taubman Health Sciences Library at the University of Michigan. She was instrumental in creating a comprehensive search strategy.

\section{Author Contributions}

Dr. Sondhi is the guarantor of the article and takes responsibility for the integrity of the work as a whole, from inception to published article. Drs. Sondhi and Kurlander and performed literature review and data extraction. Drs. Sondhi and Kurlander wrote the manuscript. All authors contributed to the editing of the manuscript. Dr. Saini designed the project and supervised it as the senior mentor. All authors approved the final version of the manuscript.

\section{Conflict of Interest}

The authors declare no conflict of interest.

\section{Financial Support}

No external funding was provided for this study.

\section{References}

1. Bucci C, Rotondano G, Hassan C, Rea M, Bianco MA, Cipolletta L, Ciacci C, et al. Optimal bowel cleansing for colonoscopy: split the dose! A series of meta-analyses of controlled studies. Gastrointest Endosc. 2014;80(4):566576 e562.

2. Kamel MA, Nguyen M, Modi R, et al. Poor bowel preparation is associated with decreased adenoma detection in the right colon and a reduced overall adenoma detection rate. Gastroenterology. 2010;138:S636.

3. Rex DK, Imperiale TF, Latinovich DR, Bratcher LL. Impact of bowel preparation on efficiency and cost of colonoscopy. Am J Gastroenterol. 2002;97(7):1696-1700.

4. Menees SB, Kim HM, Elliott EE, Mickevicius JL, Graustein BB, Schoenfeld PS. The impact of fair colonoscopy preparation on colonoscopy use and adenoma miss rates in patients undergoing outpatient colonoscopy. Gastrointest Endosc. 2013;78(3):510-516.

5. Altomare DF, Bonfrate L, Krawczyk M, Lammert F, Caputi-Jambrenghi O, Rizzi S, Vacca M, et al. The inulin hydrogen breath test predicts the quality of colonic preparation. Surg Endosc. 2014;28(5):1579-1587.

6. Mann NS, Condon DS, Leung JW. Colonic preparation correlates with fasting breath hydrogen in patients undergoing colonoscopy. Hepatogastroenterology. 2003;50(49):85-86.

7. Urita Y, Hike K, Torii N, Kikuchi Y, Kanda E, Sasajima $\mathrm{M}$, Ariki H, et al. Hydrogen breath test as an indicator of the quality of colonic preparation for colonoscopy. Gastrointest Endosc. 2003;57(2):174-177.

8. Meyer DR, Mishkin DS, Gold J. Hydrogen Breath Test (HBT) with \& without fiber supplementation to evaluate the adequacy of preparation for colonoscopy. Am J Gastroenterol. 2002;97(9 Supplement):S110-S110. Meeting abstract: 335 .

9. Meyer D, Talapanemi J, Zapiach M, Brandt LJ, Tokayer AZ. Hydrogen Breath Test (HBT) to evaluate the adequacy of preparation for colonoscopy. Gastrointest Endosc. 2001;52(5):AB83.

10. Whiting PF, Rutjes AW, Westwood ME, Mallett S, Deeks JJ, Reitsma JB, Leeflang MM, et al. QUADAS-2: a revised tool for the quality assessment of diagnostic accuracy studies. Ann Intern Med. 2011;155(8):529-536.

11. http://methods.cochrane.org/sdt/cochrane-reviews-diagnostic-test-accuracy-faq\#NotReg.

12. ASGE Standards of Practice Committee. Bowel preparation before colonoscopy. Gastrointest Endosc. 2015;81(4):781-794.

13. Tee CL, Stephensen B, Sloss A, Grieve DA. Yield of adenomas and colorectal cancers within 5 years of a negative colonoscopy: are the guidelines guiding? ANZ J Surg. 2018;88(1-2):E1-E5.

14. Kruse GR, Khan SM, Zaslavsky AM, Ayanian JZ, Sequist TD. Overuse of colonoscopy for colorectal cancer screening and surveillance. J Gen Intern Med. 2015;30(3):277283.

15. Cooper GS, Kou TD, Barnholtz Sloan JS, Koroukian SM, Schluchter MD. Use of colonoscopy for polyp surveillance in Medicare beneficiaries. Cancer. 2013;119(10):18001807.

16. Fatima H, Johnson CS, Rex DK. Patients' description of rectal effluent and quality of bowel preparation at colonoscopy. Gastrointest Endosc. 2010;71(7):1244-1252 e1242.

17. Harewood GC, Wright CA, Baron TH. Assessment of patients' perceptions of bowel preparation quality at colonoscopy. Am J Gastroenterol. 2004;99(5):839-843.

18. Rex DK, Bond JH, Winawer S, Levin TR, Burt RW, Johnson DA, Kirk LM, et al. Quality in the technical performance of colonoscopy and the continuous quality improvement process for colonoscopy: recommendations of the U.S. Multi-Society Task Force on Colorectal Cancer. Am J Gastroenterol. 2002;97(6):1296-1308.

19. Hassan C, Fuccio L, Bruno M, Pagano N, Spada C, Carrara $\mathrm{S}$, Giordanino $\mathrm{C}$, et al. A predictive model identifies patients most likely to have inadequate bowel prepa- 
ration for colonoscopy. Clin Gastroenterol Hepatol. 2012;10(5):501-506.

20. Dik VK, Moons LM, Huyuk M, van der Schaar P, de Vos Tot Nederveen Cappel WH, Ter Borg PC, Meijssen MA, et al. Predicting inadequate bowel preparation for colonoscopy in participants receiving split-dose bowel preparation: development and validation of a prediction score. Gastrointest Endosc. 2015;81(3):665-672. 